\title{
Micromachining and Characterisation of Folded Waveguide Structure at $0.22 \mathrm{THz}$
}

\author{
Rakesh Kumar Bhardwaj ${ }^{1,2}$ (D) H. S. Sudhamani ${ }^{3}$. V. P. Dutta ${ }^{2}$ Naresh Bhatnagar ${ }^{1}$
}

Received: 5 December 2018 / Accepted: 4 January 2021 / Published online: 25 January 2021

(C) The Author(s) 2021

\begin{abstract}
The demand of high-speed wireless communication has increased, which need the data rate to be in the order of Terabyte per second (Tbps) in the near future. Terahertz (THz) band communication is a key wireless communication technology to satisfy this future demand. This would also reduce the spectrum scarcity and capacity limitation of current wireless systems. Microfabricated Folded Waveguide TWTs are the potential compact sources of wide band and high-power terahertz radiation. This study primarily focuses on machining technology for $\mathrm{THz}$ waveguide components requiring ultra-high precision micromachining. Rectangular waveguides, especially Folded Waveguides (FW), are even more difficult to manufacture using conventional machining techniques due to their small size and very tight tolerances. The criticalities in micromachining of FW for $0.22 \mathrm{THz}$ have been addressed in this article. Half hard free cutting Brass IS 319- $\mathrm{H}_{2}$ was used as a work material due to its electrical and mechanical properties. Waveguide size of $0.852 \times$ $0.12 \mathrm{~mm}$ was machined within $\pm 3-5 \mu \mathrm{m}$ linear tolerances, surface roughness in the order of $45 \mathrm{~nm} R_{\mathrm{a}}$, and flatness less than half of wavelength $(<\lambda / 2)$. The split top and bottom blocks of the folded waveguide were aligned by dowel pins which matched within a tolerance of $\pm 5 \mu \mathrm{m}$. The perpendicularity and parallelism were maintained within $5 \mu \mathrm{m}$ tolerance. This work explored and established the application of micromilling as reasonably suitable for the $\mathrm{THz}$ waveguides followed by ultrasonic cleaning as deburring. It also investigated the measured folded waveguide losses which were close to simulated values.
\end{abstract}

Keywords Terahertz $(\mathrm{THz}) \cdot$ Folded waveguide $\cdot$ Tolerance $\cdot$ Surface roughness · Micromachining $\cdot$ S-parameters

Naresh Bhatnagar nareshb@mech.iitd.ac.in

Department of Mechanical Engineering, Indian Institute of Technology, New Delhi, Delhi 110016, India

2 Defence Electronics Applications Laboratory, Raipur Road, Dehradun, Uttarakhand 248001, India

3 Microwave Tube Research and Development Centre, Bengaluru, Karnataka 560013, India 


\section{Introduction}

$\mathrm{THz}$ band of frequency $0.1-10 \mathrm{THz}$ is still one of the least explored frequency bands for communication which can address many applications like medical imaging, high-definition video conferencing among mobile devices, noxious gases detection, defence communication, and security and space applications, where size and weight are of prime concerns. One of the promising structures for amplification at $\mathrm{THz}$ frequencies is the Folded Waveguide Structures (FWSs). They are derived basically from rectangular waveguides by folding in their E-plane multiple times (once in the clockwise direction and another in the anticlockwise direction) and with a beam tunnel at the centre of the straight waveguide. These modified structures are the periodic structures and have the dispersion characteristics similar to those of the coupled cavity structures which are used for microwave amplification. The FWSs are the compact source of moderate bandwidth and high-power $\mathrm{THz}$ radiation mainly because of the rugged, simple geometrical configuration [1-3]. The main reason for the least exploration of the $\mathrm{THz}$ frequency domain is the realisation of these $\mathrm{THz}$ structures. This is due to the scaling down of their dimensions with wavelength. Small dimensions make terahertz waveguide components extremely difficult to fabricate through conventional machining procedures, due to mechanical limitations imposed by waveguide dimensions and electronic limitations related to device parasitic losses during electrical measurements, which make it difficult to implement adjustable tuning and performance optimisation in THz circuits. No international standard exists for defining sizes and interfaces of rectangular metallic waveguides used in $\mathrm{THz}$ frequency band. Some proposals of size and interfaces have been published but not approved by standards making bodies like ISO, IEC, and IEEE [4, 5]. Kerr et al. [6] have defined flanges for Atacama Large Millimetre Array (ALMA) instruments in which they have suggested that variety of misalignments in waveguides associated with manufacturing processes and residual stresses associated with them as well as assembling errors lead to loss of power. They have also suggested the Torque on captive screws under various operating conditions. Though they have measured these losses for 75-110 GHz, being frequency dependent, it is even more severe in $\mathrm{THz}$ frequency band. This emphasises a critical role of linear and geometrical tolerances in realising $\mathrm{THz}$ waveguide components. However, it has become clear that the performance of these devices is now limited by not only properties of semiconductor material metallisation scheme but also mechanical micromachining that plays a major role. This has resulted in enormous amount of basic research being directed at understanding of micromachining and optimising the stringent machining parameters. Surface roughness plays a very important role in $\mathrm{THz}$ frequency band to determine the losses in addition to the conductivity of the material. Several micromachining techniques such as micromilling and micro-EDM milling have evolved to improve the surface quality. As the frequency increases, the achievable power decreases as per the well-known relation $P \alpha f^{-2}$ (power verses frequency) and the same does not hold well at THz frequencies. This is mainly because losses will increase at these frequencies. The losses in THz frequency band depend on the surface quality of the structure in addition to its conductivity. The additional losses can be attributed to the scattering and the additional path lengths. In order to reduce the losses, the surface quality of the structure has to be improved which is done using micromachining techniques. The present study is about the micromachining of a $0.22 \mathrm{THz}$ Folded Waveguide Structure and measuring its surface parameters. A 12-period FWS has been fabricated using the method of micromachining. Misalignment and surface roughness are different as surface roughness is important on the inside surfaces of waveguide for better reflection to enhance propagation of 
$\mathrm{THz}$ waves, whereas misalignment is in the context of alignment of the upper and lower block of waveguide keeping the centre of waveguide the same. In addition to that, flatness on mating surfaces should also be less than half of the wavelength $(\lambda / 2)$ to avoid leakage of energy. This leakage may also occur at flanges, where two devices are connected.

Sudhamani et al. [7-11] have published their work consisting of various aspects of design, transmission line-based equivalent circuit analysis, validation of analysis, measurements of FWSs for their dispersion, interaction impedance, and loss characteristics. Wang [12] theoretically investigated the influence of surface roughness on a conductor at $\mathrm{THz}$ frequency showing the importance of skin depth $(\delta)$, where skin depth is the depth until which the electromagnetic waves penetrate inside the waveguide surface. Figure $1 \mathrm{a}$ and $\mathrm{b}$ show the power absorption ratio at different heights of roughness $(h)$ for copper and Al alloy. Surface roughness refers to the variations in the heights of the surface in comparison to its nominal value. It is measured as average roughness $R_{a}$. For different surface profiles, $R_{a}$ may be the same but the path length can be different. Path length refers to the distance travelled by the wave along the path (profile) of the surface profile. As the path length becomes more, loss will be enhanced. The power absorption ratio is directly proportional to the surface roughness and inversely proportional to material conductivity. Tolerances are to be revaluated in the context of contemporary manufacturing processes and their capabilities. The conventional highfrequency microwave devices used for amplification such as the helix and coupled cavity, TWTSs, cannot be easily modified to operate in THz region. Researchers [13-19] have extensively used masking and deposition techniques on silicon to design and develop $\mathrm{THz}$ waveguide components. This process is particularly suitable for making $2 \mathrm{D}$ components in bulk, but tool-based micromilling can make 3D shapes on variety of materials in small quantities with surface roughness as good as $75 \mathrm{~nm} R_{\mathrm{a}}$ as is reported by Groppi et al. [20]. However, some authors $[21,22]$ have used more than two processes like micromilling and laser machining to realise the THz waveguide components. Ansoft Inc. [23, 24] describes the procedure of designing $\mathrm{THz}$ waveguides, whereas the researches published by a number of authors [25-28] have investigated micromilling in detail covering interaction of machine tool and material along with error budgeting which helps in planning the machining strategy. Other researchers [29-34] have focussed on the minute details like ploughing, minimum uncut chip thickness, and force measurements, whereas [35-40] cover specific issues like minimum
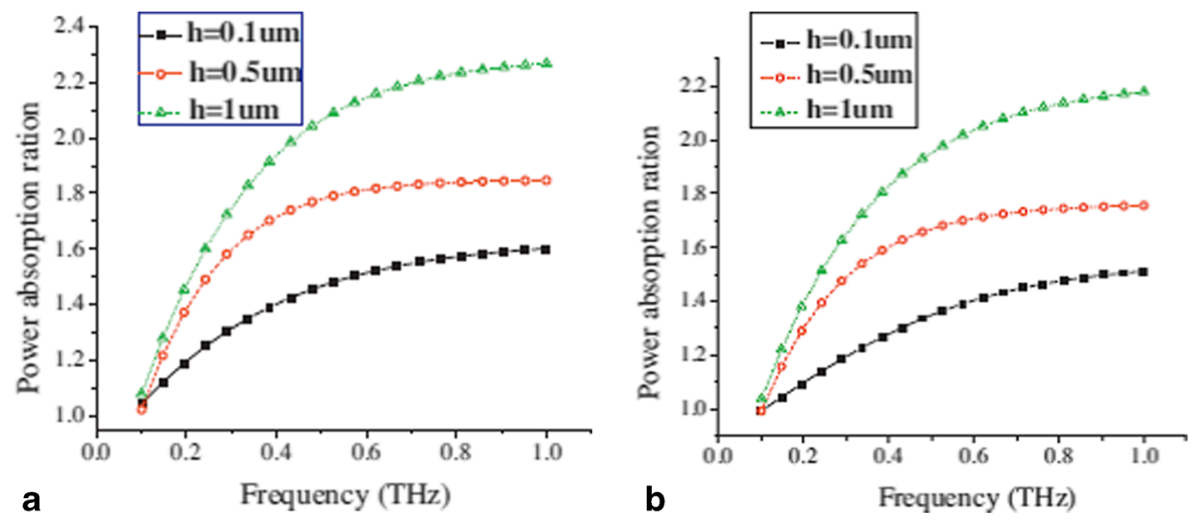

Fig. 1 Power absorption ratio for different RMS heights a for copper and $\mathbf{b}$ for aluminium. Courtesy: Wang [12]. $\delta$, skin depth $=\frac{1}{\sqrt{\pi f \mu \sigma}}$, where $\omega$ is the angular frequency $=2 \pi f ; \sigma$, conductivity; and $\mu$, permeability $=\mu_{0} \mu_{\mathrm{r}}$ 
quantity lubrication (MQL), thermal aspects, and burr formation analysis. The work presented by some authors [41-43] focusses on development of millimetre wave components and tooling required for it. Mohring et al. [44, 45] have discussed state of the art materials for machine tool structures to minimise the effect of temperature and vibration. Various mechanical as well as electrical measurement techniques and instruments are described by some authors [46, 47].

\section{Folded Waveguide Structure}

Several waveguide structures including the $220 \mathrm{GHz}$ FWS were taken up to study their fabrication using micromachining methods. The folded waveguide structure was designed from 170 to $280 \mathrm{GHz}$ (cold pass band) initially by following an approach [1-3] and fine-tuned with the simulation using Eigen mode solver of CST Studio software which is based on finite integration technique. The electronic aspects of FWS have already been published by the authors in [7-11]; hence, this study was focussed on the mechanical aspects of the folded waveguides and the derived circuits. Achieving the tolerances of $\pm 3-5 \mu \mathrm{m}$, surface roughness in the order of 40-45 $\mathrm{nm} R_{\mathrm{a}}$, and flatness, perpendicularity, squareness, and positional tolerances of $\pm 5 \mu \mathrm{m}$ is equally critical for the performance of these electromechanical components and the derived circuits. The six-period FWS was fabricated and measurements were carried out. The loss was measured in terms of S-parameters. The details of the fabrication/measurements are given in the following sections. Figure 2 a shows the line sketch of FWS structure for 12 periods. It is a derived structure from rectangular waveguide with broadside dimension $a$ and narrow side dimension $b$. The pitch $p$ is the distance between successive beam crossings and it is responsible for achieving the required delay ratio. This delay ratio is a factor which is proportional to the pitch (period)/path of the electromagnetic wave along the folding between the successive beam crossings. At synchronisation where the velocity of the beam is close to the axial velocity of the electromagnetic wave in the FWS, the beam interacts with the electromagnetic wave as it progresses through the beam tunnel, causing velocity modulation and density modulation resulting in the formation of the electron bunches. These bunches move with reduced velocity and give energy to the wave and the wave grows resulting in the amplification. In this case, the FWS is designed with cold pass band from 170 to $280 \mathrm{GHz}$ and the operating band width is from 220 to $250 \mathrm{GHz}$. The upper and lower blocks of realised hardware are shown in Fig. 2 b.
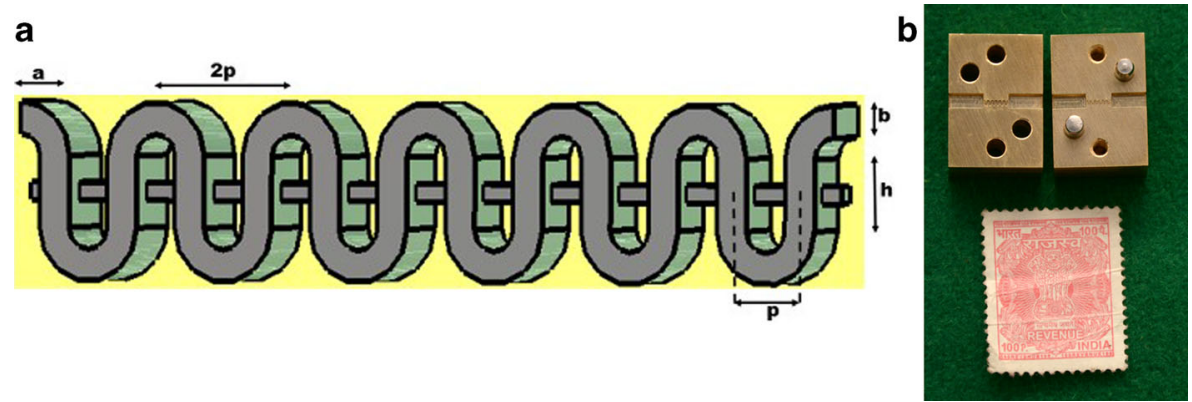

Fig. 2 a Line sketch of the FWG, courtesy: Sudhamani et al. [7]. b Upper and lower blocks of FWG 


\section{Work Material for FWS}

Half hard free cutting Brass IS 319-H2 (Cu: 61\%, Zn: 36\%, Pb: 3\%) was selected for FWG structure due to its high strength, corrosion resistance, and good dimensional stability over a long period of time. This alloy is suitable for waveguides at higher frequencies due to its electrical conductivity $\left(1.59 \times 10^{7} \mathrm{~S} / \mathrm{m}\right)$ and machinability. This alloy is known as alpha $(\alpha)$ brass and it is annealed before cold working and is subjected to stress relief annealing after cold working to prevent season cracking. Inclusion of lead in the alloy makes cutting free and zinc at $36 \%$ completely dissolves in the solution and makes a continuous solid solution. The finished part is gold (electrical conductivity $=1.59 \times 10^{7} \mathrm{~S} / \mathrm{m}$ ) plated with a thickness of 1-2 $\mu \mathrm{m}$ to further increase the electrical conductivity and hence better electronic performance.

\section{Micromachining Setup}

The micromachining of waveguide was carried on a Kern CNC micromilling machine as shown in Fig. 3a, having Heidenhain TNC 530 Controller. Tools of diameter as small as 70 $100 \mu \mathrm{m}$ with tool nose radius of $2 \mu \mathrm{m}$ were used. It is important to use the actual instantaneous diameter and reducing length of the tool during cutting through online measurement and compensation. The scanning electron microscope image of the micro-end mill cutter is shown in Fig. 3b. Machining parameters like cutting speed, feed, and depth of cut were optimised using ANOVA as well as the Taguchi method and were experimentally verified to achieve the required linear tolerances, geometrical tolerances, and surface roughness. Long-term distortion in the waveguide can result in a loss of tolerance of waveguide although its initial flatness meets the specifications. To take care of distortion during and after machining and to prevent work hardening effect due to cutting forces, well-sharpened cemented solid carbide end mills were used on the CNC milling machine. To prevent distortion and overheating in the thin sections, controlled feed rate and depth of cut along with a minimum quantity lubrication (MQL) was used. This has also prevented burnishing-glazing effect on the machined surface.

Free cutting Brass block was machined on six faces, using a high precision milling machine within $5 \mu \mathrm{m}$ parallelism and within 20-min squareness. 'Kern' recommended collets and tool holders were used for the micromilling of all the folded waveguides. The upper and lower

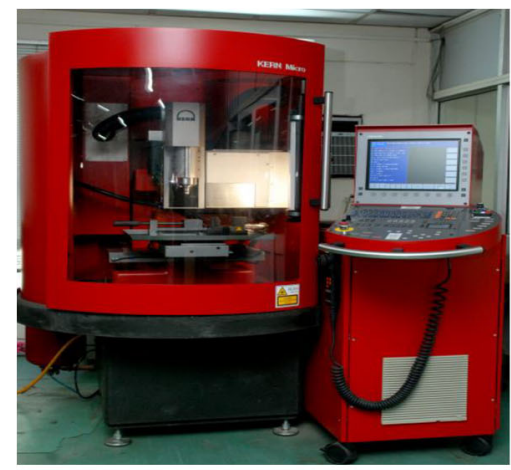

a

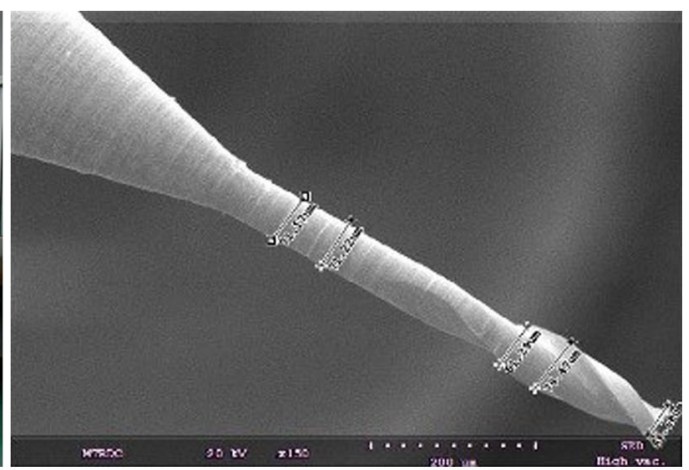

b

Fig. 3 a Kern CNC micromilling machine. b Carbide micro-end mill of 70-100 $\mu \mathrm{m}$ 
blocks are aligned by dowel pins having positional tolerances within $\pm 5 \mu \mathrm{m}$ under a tool maker's microscope having magnification of $\times 50-100$. Lapping was done on the mating surfaces of the upper and lower blocks using the SpeedFam double sided lapping machine with abrasiveness of up to 4000 grit size in kerosene vehicle. The fitment of dowel pins is a critical work and required clean environment and operator's skill.

\section{Measurements}

\subsection{Measurement of Mechanical Parameters}

The surface profiler, BRUKER Contour GT K-10 as shown in Fig. 4a, was used to measure roughness value. The scanning electron microscopy (SEM) image of the FWG structure is shown in Fig. 4b, which clearly shows microburrs at a magnification of $\times 100$.

The microburrs were cleaned using ultrasonic cleaning at $20-400 \mathrm{kHz}$ frequency in a kerosene medium. Linear dimensions of the broad side of waveguide $a$ as well as the narrow side of waveguide cross-section $b$ were measured using mechanical as well as optical methods. Similarly, other design parameter values like peak to peak height of folded waveguide structure and inner height of the folded waveguide structure were also measured using optical methods. Flatness was measured using sodium monochromatic light system as well as optical methods. The obtained flatness is less than $0.3 \mu \mathrm{m}$. The linear tolerances were found within \pm 3-5 $\mu \mathrm{m}$ and the surface roughness in the order of $45 \mathrm{~nm} R_{\mathrm{a}}$. The inside waveguide surface topography is shown if Fig. $5 \mathrm{a}$ and $\mathrm{b}$ at magnifications of $\times 60$ and $\times 10,000$ respectively. The cutting tool marks can be seen at high magnification. Table 1 describes the design parameters, measured parameters, and deviations from design values. The surface roughness at various critical areas is also shown in this table.

\subsection{Loss (S-Parameter) Measurements}

Various straight as well as folded waveguide structures were fabricated for different frequencies and their loss measurement was carried out. The loss measurement for $220 \mathrm{GHz}$ FWS was reported in the present study. The two halves of the 12-period FWS was assembled and was

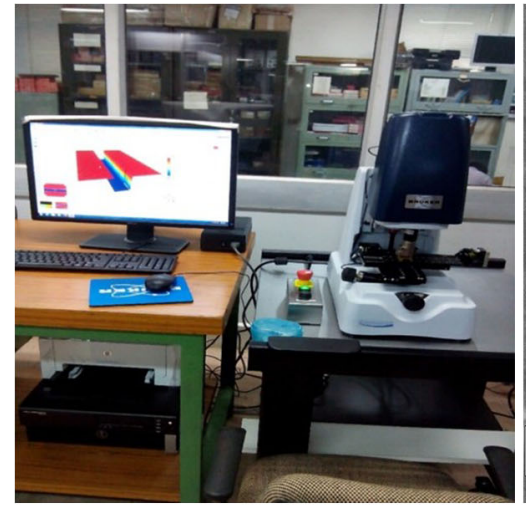

a

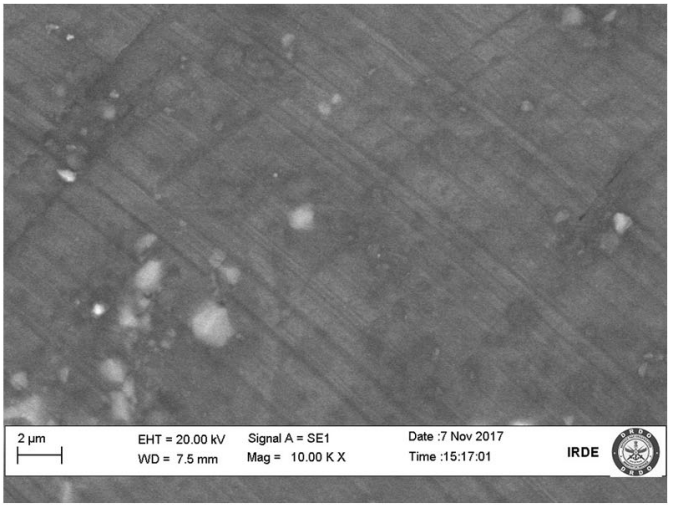

b

Fig. 4 a Bruker Contour GT surface profiler. b SEM image folded waveguide structure at $\times 100$ 


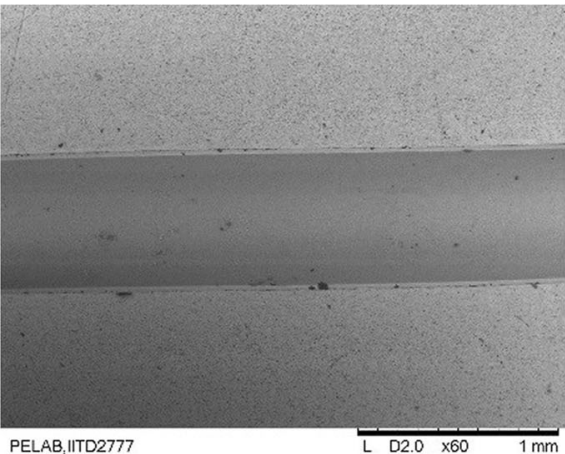

a

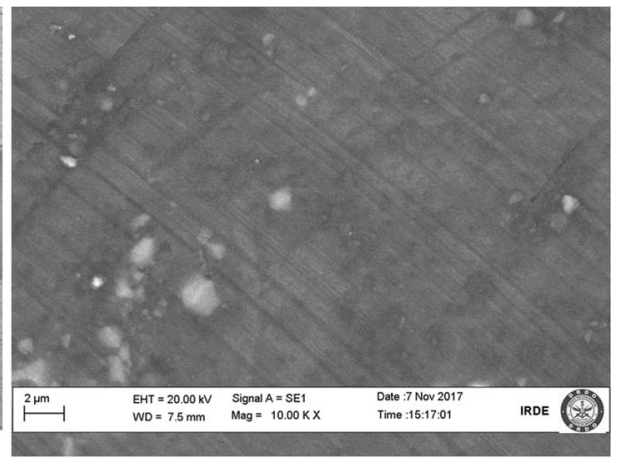

b

Fig. 5 a Surface topography of FWG structure at $\times 60$. b Topography of inner W/G surface at $\times 10,000$

connected to WR-04 waveguides at both ends. This was connected to PNA Network analyser N5222A as shown in Fig. 6a. The loss measurement of 12 periods for this structure $S_{21}$ is shown in Fig. 6b. In this particular case, measurements were carried out by connecting directly the WR-04 waveguides to the 12-period FWS which includes the loss due to the mismatch of the adapter at both ends. This loss has to be deducted to obtain the loss FWS. The same was simulated and the actual loss of the FWS was obtained. The actual loss per period is approximately $0.42 \mathrm{~dB}$ (average value) for this structure. This loss causes reduction in gain and the power. It is also known that the maximum $R_{a}$ allowed should be less than half of the skin depth.

\section{Conclusions}

In this paper, microfabrication of a Folded Waveguide Structure (FWS) at $0.22 \mathrm{THz}$ has been carried out and mechanical parameters were studied. The mechanical measurements show good agreement between measured and design values. The linear tolerances are within $\pm 3-5$ $\mu \mathrm{m}$. The upper and lower halves of the folded waveguide were aligned within $\pm 5 \mu \mathrm{m}$ which helps in reducing plumbing losses. The surface roughness achieved inside the waveguide by end milling was of the order of $45 \mathrm{~nm} R_{\mathrm{a}}$ by optimised machining parameters. This roughness

Table 1 Mechanical parameters of fabricated Folded Waveguide Structure

\begin{tabular}{|c|c|c|c|c|}
\hline Design parameter & $\begin{array}{l}\text { Design value } \\
(\mathrm{mm})\end{array}$ & $\begin{array}{l}\text { Measured } \\
\text { value }(\mathrm{mm})\end{array}$ & $\begin{array}{l}\text { Deviation } \\
(\mathrm{mm})\end{array}$ & $\begin{array}{l}\text { Surface } \\
\text { roughness }\left(R_{\mathrm{a}}\right)\end{array}$ \\
\hline Period & 0.560 & 0.563 & 0.003 & $42 \mathrm{~nm}$ \\
\hline $\begin{array}{l}\text { Broad side waveguide dimension ' } a \text { '/2 for each } \\
\text { half part (depth) }\end{array}$ & 0.425 & 0.430 & 0.005 & $45 \mathrm{~nm}$ \\
\hline Narrow dimension of the waveguide ' $b$ ' & 0.120 & 0.125 & 0.005 & $41 \mathrm{~nm}$ \\
\hline $\begin{array}{l}\text { Value ' } b \text { ' at depth (each halves - measure of } \\
\text { taper) }\end{array}$ & 0.120 & 0.090 & 0.030 & $45 \mathrm{~nm}$ \\
\hline Beam hole width ' $a_{1}$ '/2 (each half part) & 0.15 & 0.153 & 0.003 & \\
\hline Beam hole height, ' $b_{1}$ ' & 0.075 & 0.078 & 0.003 & - \\
\hline $\begin{array}{l}\text { Peak-peak height of Folded Waveguide } \\
\text { Structure }\end{array}$ & 0.726 & 0.723 & 0.003 & - \\
\hline Inner height of the FWS & 0.513 & 0.518 & 0.005 & - \\
\hline
\end{tabular}




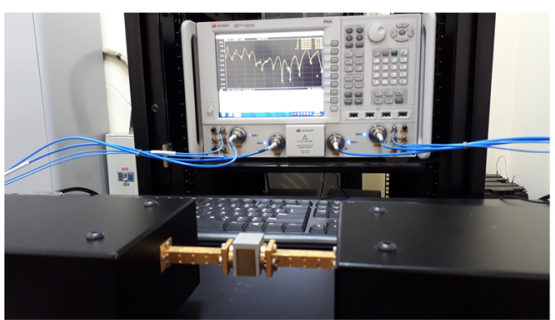

a

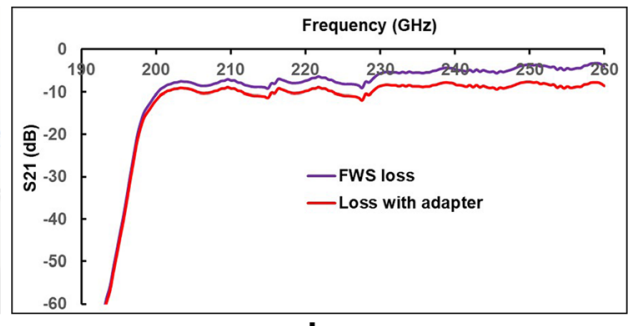

b

Fig. 6 a Measurement of S-parameter on network analyser. b Loss measurements of 12-period FWS

value is excellent as it helps in reducing the conductor loss, because the material properties like conductivity and permeability are fixed for the designated frequency of operation in the $\mathrm{THz}$ region. The folded waveguide was also tested for its loss characteristic response by measuring the S-parameters. Loss per period achieved is approximately $0.42 \mathrm{~dB}$ which is a reasonably good result. From the results, it is clear that micromilling with appropriate machining strategy is still a viable method for achieving the required parameters for this class of structures. Process can be further improved to improve the surface finish as well as remove the tapering of ' $b$ ' dimension from 0.12 to $0.09 \mathrm{~mm}$ at the depth of each halves which may be due to left over microburr. This work shows the path for the manufacturing of the devices for $\mathrm{THz}$ frequencies for futuristic applications. The prediction of the power output using this structure involves the exact modelling of the surface profiles for all the periods in the PIC simulator. The present work can be utilised for prediction of power amplification using PIC simulations.

Acknowledgements The authors are thankful to Director DEAL, DRDO, Director, MTRDC, DRDO, and Director IIT Delhi for their support during the research.

Open Access This article is licensed under a Creative Commons Attribution 4.0 International License, which permits use, sharing, adaptation, distribution and reproduction in any medium or format, as long as you give appropriate credit to the original author(s) and the source, provide a link to the Creative Commons licence, and indicate if changes were made. The images or other third party material in this article are included in the article's Creative Commons licence, unless indicated otherwise in a credit line to the material. If material is not included in the article's Creative Commons licence and your intended use is not permitted by statutory regulation or exceeds the permitted use, you will need to obtain permission directly from the copyright holder. To view a copy of this licence, visit http://creativecommons.org/licenses/by/4.0/.

\section{References}

1. J. H. Booske, M. C. Converse, C. L. Kory, C. T. Chevalier, D. A. Gallagher, K. E. Kreischer, V. O. Heinen, S. Bhattacharjee, Accurate parametric modeling of folded waveguide circuits for millimeter-wave traveling wave tubes. IEEE Trans. Electron Dev., vol. 52, no. 5, pp. 685-694, May 2005.

2. Xue Qianzhong, Meng Xin, Wang Shujian, Li Ke, Liu Wenxin, Analysis of Two-Beam Ka Band Folded Waveguide Travellinh-Wave Tube. J Infrared Milli Terahz Waves, pp. vol:36: 31-41, 2015.

3. Ruilin Zheng and Xuyuan Chen, Parametric Simulation and Optimization of Cold-test Properties for a 220 GHz Broadband Folded Waveguide Traveling-wave Tube. J. Infrared Milli Terahz Wave, pp. 945-958, 2009.

4. J.L Hesler, A.R. Kerr, W. Grammer, and E. Wollack, Recommendations for Waveguide Interfaces to 1 THz, 18 ${ }^{\text {th }}$ International Symposium on Space Terahertz Technology, pp. 100-103, 2008.

5. N M Ridler and R A Ginley, A review of the IEEE 1785 Standard for Rectangular Waveguides above 110GHz, 978-1-5386-2747-1/17, IEEE, 2017. 
6. A R Kerr, E Wollack, N Horner, Waveguide Flanges for ALMA Instrumentation, ALMA Memo No. 278, National Radio Astronomy Observatory, Charlottesville, VA 22903, 2009.

7. H. S. Sudhamani, R Bhardwaj, J. Balakrishnan and S. U. M Reddy, Study of Passband and Stopband Properties of Sheet Beam Folded Waveguide Structures. IEEE Trans. Electron Devices. vol. 66, no. 5, pp. 2401-2408, 2019

8. H. S. Sudhamani, J. Balkrishnan, and SUM Reddy, Dispersion measurements of $220 \mathrm{GHz}$ FWSs, Proc. IEEE Int. Vacuum Electronic Conf., South Korea 2019.

9. H. S. Sudhamani, J. Balkrishnan, and SUM Reddy, Loss measurements of $220 \mathrm{GHz}$ FWSs, Proc. IEEE Int. Vacuum Electronic Conf., South Korea, 2019.

10. H. S. Sudhamani, J. Balakrishnan and S. U. M Reddy, Investigation of Instabilities in a Folded Waveguide Sheet Beam TWT. IEEE Trans. Electron Devices. vol. 64, no. 10, pp. 4266-4271, 2017.

11. H. S. Sudhamani, J. Balakrishnan, S. U. M Reddy, PIC simulations of folded waveguide slow wave structures for THz TWTs, in Proc. $4^{\text {th }}$ Int. Electronic Warfare Conf.(EWCI), Bengaluru, India, Feb 2016, pp. 95-97, 2016.

12. Zhihui Wang, The Influence of surface roughness on conductor at terahertz frequencies, Optik vol.125 pp.3237 - 3240, 2014.

13. Lihan Chen, Alex Arsenovic, James R. Stanec, Theodore J. Reck, Arthur W. Lichtenberger, Robert M. Weikle II, and Scott Barker. A Micromachined Terahertz Waveguide $90^{\circ}$ Twist, IEEE Microwave and Wireless Components Letters, Vol. 21, No.5, pp. 234-236, 2011.

14. Coroline E. Colins, Robert E. Miles, John W. Digby, Geoff Parkhurst, Roger D. Pollard, J. Martyn Chamberlain and D. Paul Steenson; Micro-machined "Snap-Together" Rectangular Waveguide For terahertz Circuits, IEEE pp-176-178, 1998.

15. Victor M. Lubecke, Koji Mizuno and Gabriel M. Rebeiz, Micromachining for terahertz Applications. IEEE Transactions on Microwave Theory and Techniques, Vol. 46, No.1821-1831, 11 November 1998.

16. James R. Stanec and Scott Barker, Fabrication and Integration of Micromachined Submillimeter-Wave Circuits. IEEE Microwave and Wireless Components Letters, Vol. 21, No. 8, pp.409-411, August (2011).

17. Shuang Lie, Jiang Hu, Yong Zang Li Li, Wei Zhao, Ruimin Xu, Quan Xue, Silicon micromachined Waveguide-Hybrid Coupler at Terahertz Frequency Band. J Infrared Milli Terahz Waves, vol. 36, pp.7097192015.

18. James T. Do, Qiang Yu, Jeffrey L. Hesler and N. Scott Barker, A 330-500 GHz Micro-Machined Directional Coupler, IEEE, pp. 1-3, 2015.

19. Y.F. Zhou, J. Hu, S. Liu, and Y. Zhang, A Terahertz-band Branch Waveguide Directional Coupler Based on Micro-machining, IEEE, pp. 213-217, 2014.

20. Christopher E. Groppi, Brian Love, Matthew Underhill, Christopher Walker, Automated CNC Micromachining for Integrated THz Waveguide Circuits, 21ST International Symposium on Space Terahertz Technology, Oxford, 23-25 March, 2010.

21. James T. Do, Robert Barchfeld, Neville C. Luhmann and Xiaoguang Liu, A 75-110 GHz Micro Machined High-Q Tunable Filter, IEEE, pp. 1-3, 2015.

22. Samantha M. Lewis, Emilio A. Nanni and Richard J. Temkin, Direct Machining of Low-Loss Waveguide Components With an RF Choke, IEEE microwave and Wireless Components Letters, Vol. 24, No. 12, pp. 842-844, 2014.

23. Ansoft corporation, Getting started with HFSS a waveguide T-Junction, Ansoft corporation, 225 west station square, Suite200, Pittsburgh, USA, 2004.

24. Computer Simulation Technology (CST) GmbH.: www.cst.de on 21Nov. 2018.

25. S.J. Zhang, S. Too, S.J. Wang, and Z.W. Zhu, A review of surface roughness generation in ultra-precision machining. International Journal of Machine Tools \& Manufacture, vol. 91, pp.76-95, 2015.

26. J. Chae, S. S. Park, T Freiheit, Investigation of micro-cutting operations; International Journal of Machine Tools \& Manufacture, vol. 46, pp.313-332, 2006.

27. $\mathrm{C}$ Brecher, $\mathrm{M}$ Esser, $\mathrm{S}$ Witt, Interaction of manufacturing process and machine tool, CIRP AnalsManufacturing Technology, vol. 58, pp. 588-607, 2009.

28. L. Uriate, A Herrero, M ZAtarain, G. Santiso, L.N. Lopez de Lacalle, A. Lamikiz and J. Albizuri, Error budget and stiffness assessment in a micromilling machine equipped with tools less than $0.3 \mathrm{~mm}$ in diameter. Precision Engineering, vol.31, pp. 1-12, 2009.

29. Fernado Branado e Oliveira, Alessandro Roger Rodrigues, Reginaldo Teixeira Coelho, Adriano Fagali de Souza, Size effect and minimum chip thickness in micro milling. International Journal of Machine Tools \& Manufacture, vol.89, pp. 39-54, 2015.

30. A J Mian, N Driver, P.T. Mativenga, Identification of factors that dominate size effect in micro-machining. International Journal of Machine Tools \& Manufacture, vol. 51, pp. 383-394, 2011.

31. M Malekian, M G Mostofa, S S Park, M B G Jun, Modelling of minimum uncut chip thickness in micro machining of aluminum. Journal of Material Processing Technology, vol. 212, pp. 553-559, 2012. 
32. Hui Taek Yun, Segon Heo, Min Kyu Lee, Byung-Know Min, Sang Jo Lee, Ploughing detection in micromilling process using the cutting force signal. International Journal of Machine Tools \& Manufacture, vol. 51, pp. 377-382, 2011.

33. P. Rodriguez, J E Labarga, A new model for the prediction of cutting forces in micro-end-milling operations. Journal of Material Processing Technology, vol. 213, pp. 261-268, 2013.

34. Ali Mamedov, Ehsan Ayegh K, Ismile Lazoglu, Machining forces and tool deflection in micro milling. Procedia CIRP, vol. 8, pp. 147-151, 2013.

35. Kuan-Ming Li, Shih-Yen Chou, Experimental evaluation of minimum quantity lubrication in near micro milling. Journal of Material Processing Technology, vol. 210, pp. 2163-2170, 2010.

36. E Creighton, A. Honegger, A. Tulsian, D. Mukhopadhyay, Analysis of thermal errors in a high-speed micro-milling spindle. International Journal of Machine Tools \& Manufacture, vol. 50, pp. 386-393, 2010.

37. J C Aurich, D Dornfeld, P J Arrazola, V Franke, L Leitz, S Min, Burr-Analysis and removal, CIRP AnnalsManufacturing Technology, vol. 58, pp. 519-542, 2009.

38. Guillem Quintana, Joaquim Ciurana, Chatter in machining processes: A review. International Journal of Machine Tools \& Manufacture, vol. 51, pp. 363-376, 2011.

39. S J Zang, S To, G Q Zang, Z W Zhu, A review of machine-tool vibration and its influence upon surface generation in ultra-precision machining. International Journal of Machine Tools \& Manufacture, vol. 91, pp. 34-42, 2015.

40. Kai Egashira, Shigeyuki Hosono, Sho Takemoto, Yusuke Masao, Fabrication and cutting of cemented tungsten carbide micro-cutting tools. Precision Engineering, vol. 35, pp. 547-553, 2011.

41. Rakesh Kumar Bhardwaj, V P Dutta, Naresh Bhatnagar, Mechanical Engineering Challenges in Making Terahertz Frequency Band Next Frontier for Wireless Communication, Defence Technology Spectrum, vol.1, DESIDOC 2015.

42. Rakesh Kumar Bhardwaj, V P Dutta, PP Marwaha, Machining of MMW components using CAM softwareA case study, 18th Production engineers convention, IEI, Jabalpur, 2003.

43. Rakesh Kumar Bhardwaj, V P Dutta, P P Marwaha, Effect of surface roughness on machined WR-10 wave guide cavities, Advances in microwaves, proceedings of the National symposium, IT BHU, pp.295-299, 2007.

44. Hans-Christian Mohring, Christian Brecher, Eberhard Abele, Jurgen Fleischer, Materials in machine tool structure, CARP Annals-Manufacturing Technology, vol. 64, pp. 725-748, 2015.

45. http://www.kern-microtechnic.com dated 5th August 2017.

46. www.bruker-nano.com/Bruker Nano Surface Division, Tucson, AZ USA dated $12^{\text {th }}$ June 2015.

47. Thomas Kurner, Alexender Fricke, Sebastian Rey, Phillippe Le Bars, Thomas Kleine-Qstmann, Measurements and Modelling of Basic Propagation Characteristics for Intra-Device Communication at $60 \mathrm{GHz}$ and $300 \mathrm{GHz}$, Journal of Infrared, Millimeter, and Terahertz Waves, Vol 36, pp. 144-158, 2015.

Publisher's Note Springer Nature remains neutral with regard to jurisdictional claims in published maps and institutional affiliations. 